From the above table it is seen that in ten cases out of thirteen, the formula I have proposed gives results clo er than $\mathrm{Mr}$. Stevenson's, while the means differ by a quite insignificant amount.

If then, as seems probable on all grounds, the higher we ascend, the slower the increase of the velocities with the heights, Mr. Stevenson's formula, $\frac{v}{V}=\left(\frac{h}{H}\right)^{\frac{1}{2}}$, should hold for a level somewhat higher than 775 feet, and not below it. Above that, again, a formula, $\frac{v}{V}=\left(\frac{h}{H}\right)^{\frac{1}{3}}$ should apply; and finally, the formula, $\frac{v}{V}=\left(\frac{h}{H}\right)^{1}$, recommended in my paper.

I cannot believe, however, that the formula $\frac{v}{V}=\left(\frac{h}{H}\right)^{\frac{1}{2}}$ holds up to such a comparatively large height as this inference would postulate, since it gives such an excessive value at 1600 feet with Vettin's data (more than twice that observed), and I can only conclude, therefore, until experiments in a free atmosphere corroborate Mr. Stevenson's data from Arthur's Seat, that these latter do not correctly represent the actual rate of increase in the velocity between such levels in the atmosphere, away from the disturbing influences of mountains and valleys.

In any case, however, I must enter a distinct protest against having my name prefixed to the pressure formula $\frac{f}{F}=\sqrt[4]{\frac{h}{H}}$. If $\mathrm{Mr}$. Stevenson carefully examines my paper, he will nowhere find the remotest allusion to such a formula. The formula for the velocity which I there recommended for the higher levels, was in fact shown to be directly deducible from Mr. Stevenson's first formula for the pressure, viz. $\frac{f}{F}=\sqrt{\frac{h}{H}}$, to which it is exactly equivalent on the ordinary assumption that $\frac{f}{F}=\frac{v^{2}}{V^{2}}$.

Moreover, the paradoxical result which $\mathrm{Mr}$. Stevenson arrived at in violation of this assumption, viz. that the same formula was practically applicable both to force and velocity, is controverted by the conclusion entertained in his letter, that the formula $\frac{v}{V}=\sqrt{\frac{h}{H}}$ agrees best with the recorded results of velocity, and the formula $\frac{f}{F}=\frac{h}{H}$ with those of pressure.

While these two formula can hardly be called the same, it is somewhat striking to find that on the assumption force varies as (velocity $)^{2}$, which is supposed to be annulled by the diminished density as we ascend, they are identical.

Finally, Mr. Stevenson has ev dently quite misunderstood my allusion to sea-level. When I spoke of sea-level, I simply meant, the approximate equivalent to the level of the sea on land, as at Berlin for example, where Vettin's observations were made. When Mr. Stevenson therefore maintain; that the velocity of the wind at 100 feet above sea-level over land, is probably not so great as that near the surface over the sea, he entirely misses the point of the argument, which lies in the relatively excessive velocity of the wind at 100 feet above, to that near the surface, over land which lies approximately at sea-level.

The very fact mentioned by $\mathrm{Mr}$. Stevenson regarding the greater friction encountered by air in passing over land than over water, as well as the results of his experiments, point to a considerable increase in the velocity from the surface to an elevation of 100 feet above it. For the very same reason, I should expect to find a more moderate increase up to the same height over water.

E. DOUglas Archibald

\section{On the Formation of Mudballs}

The letter from Mr. Hart in NATURE, vol. xxvii. p. 483 , on the natural formation of snowballs, has recalled to my memory the similar formation of balls of mud.

About eight miles south of Bromley in Kent the soil is clayey, and after rain the country lanes are apt to be very muddy. Some five or six years ago there was a very violent storm of rain, whether or not accompanied with melting of snow I cannot now remember. The steep lanes were in many places regularly scoured with water, and it looked afterwards as though the whole surface had in places been a sheet of water, for the soil was quite washed off and the flints were left bare. After this storm $m y$ brother and I noticed in the lanes a considerable number of mudballs, usually almost perfectly spherical, but in some cases with a tendency to a cylindrical shape. They varied in size from small pellets up to four or five inches in diameter. On seeing the first one or two, they looked to us like the handiwork of some boy with an enthusiasm for mud pies, but the number of them, and the fact that they were always found on the slopes of hills proved them to be a natural formation. They were formed throughout of soft clayey mud, and I do not remember finding any nucleus in the middle when we cut them open. We concluded that they were formed by accretion to pellets of mud washed down the hillside and rolling as they went. I have only once since seen a similar ball, and that was in a furrow in a ploughed field in the same country; it is possible that this ball may have been made inside an agricultural roller, although there were no marks on the field of recent rolling and there had been heavy rain. The comparative rarity of the appearance of these balls seems to show that they can only be formed with some precise degree of stickiness of the mud. Closely similar are the marvellously spherical balls of matted vegetable fibre to be found on the seabeach in some places. Sir Anthony Musgrave informed me that on the beach in Australia, I think near Adelaide, he had seen tens of thousands of such balls, all perfectly spherical. It seems rather obscure why the fibres should begin to mat together in such a form as to be rolled by the surf, but the perfection in shape is clearly due to incessant rolling. It is probable that, with a flat bath and some cocoanut fibre or oakum, the process of formation might be watched, but I have never tried the experiment. It is very common to see after rain matted lines of such objects as pine-leaves or the flowers of lime-trees, but I have never seen any apparent tendency to rolling, and such lines are left lying flat after the water has drained off. Cambridge, March 23

\section{Snow Rollers}

THE phenomenon described in NATURE, vol. xxvii. p. 483 , under the title of "Natural Snowballs," is known to British meteorolegists under that of snow rollers, and as the latter agrees more closely with the phenomenon, I venture to plead for its adoption.

I believe that the first person who carefully examined their formation was that excellent and venerable observer, the Rev. Dr. Clouston of Sandwick Manse, Orkney, and I am under the impression that he published a description of their formation in an early number of the Philosophical Magazine. He has observed them on the lawn at San wick more than once, and has always noticed the hollowness at the ends; in fact, he described them to me as resembling ladies' white muffs.

I remember only one instance of their being reported in Eng. land, namely in the following letter from the late Adimiral Sir F. W. Grey, which appeared in the Meteorological Magazine for May, 1876

62, Camden Square, N.W.

G. J. SYMONS

SIR, - The snowstorm of Thursday night (April 13, I876) was marked by one circumstance which $I$ have never witnessed before, though it may not be uncommon. It was this :-

On Friday morning I observed th it for a considerable distance, and following a regular line, the lawn, to leeward of the house, was strewed with masses of snow like boulders, varying from the size of a snowball to a cubic foot at least, and as the snow melted, a track either straight or curved led up to the large ones, following, apvarently, the direction of the wind. I had observed before dusk that the eddies of the wind and the swirl; of the snow were very marked, and I have since heard from a friend who observed the same thing, that he saw the snow rolled along by the wind, and forming masses such as I have described.

As I have said, I know not whether this has been observed in other cases, and perhaps it may interest you to have this account of it.-Yours faithfully,

Lynwood, Sunningdale, Staines, April 16

\section{Incubation of the Ostrich}

IT seems strange that there should have existed an uncertainty in the mind of an ornithologist as to the mode of incubation of the ostrich in confinement at the Cape of Good Hope. The habits of the birds are of course as familiar to the ostrich-farmers 